\title{
NmPin from the marine thaumarchaeote Nitrosopumilus maritimus is an active membrane associated prolyl isomerase
}

\author{
Lukas Hoppstock ${ }^{1 \dagger}$, Franziska Trusch ${ }^{2 \dagger}$, Christoph Lederer $^{1}$, Pieter van West ${ }^{2}$, Martin Koenneke ${ }^{3}$ and Peter Bayer ${ }^{1 *}$ (D)
}

\begin{abstract}
Background: Peptidyl-prolyl isomerases (PPlases) are present in all forms of life and play a crucial role in protein folding and regulation. They catalyze the cis-trans isomerization of the peptide bond that precedes proline residues in numerous proteins. The parvulins, which is one family of PPlases, have been extensively investigated in several eukaryotes. However, nothing is known about their expression, function and localization in archaea.

Results: Here, we describe the endogenous expression, molecular structure, function and cellular localization of NmPin, a single-domain parvulin-type PPlase from Nitrosopumilus maritimus. This marine chemolithoautotrophic archaeon belongs to the globally abundant phylum Thaumarchaeota. Using high resolution NMR spectroscopy we demonstrate that the 3D structure of NmPin adopts a parvulin fold and confirmed its peptidyl-prolyl isomerase activity by protease-coupled assays and mutagenesis studies. A detailed topological analysis revealed a positively charged lysine-rich patch on the protein surface, which is conserved in all known parvulin sequences of thaumarchaeotes and targets NmPin to lipids in vitro. Immunofluorescence microscopy confirms that the protein is attached to the outer archaeal cell membrane in vivo. Transmission electron microscopy uncovered that NmPin has a uniform distribution at the membrane surface, which is correlated with a native cell shape of the prokaryote.

Conclusion: We present a novel solution structure of a catalytically active thaumarchaeal parvulin. Our results reveal that a lysine-rich patch in NmPin mediates membrane localization. These findings provide a model whereby $\mathrm{NmPin}$ is located between the archaeal membrane and the surface layer and hence suggest proteins of the S-layer as the key target substrates of this parvulin.
\end{abstract}

Keywords: Parvulin, NmPin, Nitrosopumilus maritimus, Thaumarchaeota, Archaea, PPlase, Isomerase, Membrane

\section{Background}

Proteins are biomolecules acting as scaffolds, signal transmitters or catalysts of chemical reactions in living cells. Before they can commence their tasks they need to undergo intensive folding steps to adopt their proper threedimensional topologies. The cis-trans isomerization of peptide bonds in Xaa-Pro moieties (Xaa being any amino acid) is essential but also a rate-limiting step in such protein folding processes [1]. Due to a high energy barrier $(\sim 20 \mathrm{kcal} /$ mol) between the two almost isoenergetic conformers, the

\footnotetext{
* Correspondence: peter.bayer@uni-due.de

${ }^{\dagger}$ Equal contributors

${ }^{1}$ Department of Structural and Medicinal Biochemistry, Centre for Medical Biotechnology, University of Duisburg-Essen, Universitätsstr. 1-4, 45141 Essen, Germany

Full list of author information is available at the end of the article
}

rate of interconversion is extremely slow $[1,2]$. However, an important group of proteins, called the peptidyl-prolyl cis-trans isomerases (PPIases), catalyze and accelerate this reaction and thereby essentially control the folding of proteins $[3,4]$. PPIases are grouped in three classes - the cyclophilins (CYP) [5], FK506-binding proteins (FKBP) [6], and the parvulins [7] - according to their topology [8].

Parvulins, a group of small globular proteins with a distinctive $\beta \alpha_{3} \beta \alpha \beta_{2}$-fold, are found in all kingdoms of life $[9,10]$. By far the most well-studied parvulin is the human Pin1, a phosphorylation-dependent molecular switch, which is involved in cell cycle and transcriptional regulation as well as protein quality control [11-14]. Pin1 is reported to influence ageing, cancer development and neurodegenerative processes in Alzheimer's and Parkinson's diseases (reviewed in [15]). Prokaryotic parvulins, 
such as the structurally characterized SurA [16-19] and PpiD [20, 21] from Escherichia coli, PrsA from Bacillus subtilis [22-24] or PrsA from Staphylococcus aureus [25], are involved in folding and maturation of extracellular, periplasmic and outer membrane proteins. In contrast to eukaryotic Pin-type parvulins found in yeast, metazoans and multicellular archaeplastidae, the prokaryotic representatives lack a recognition site for phosphorylated target residues [20, 25-27].

Except for the smallest member and archetype of the parvulin family, Par10 from E. coli [7, 9, 27], all proteins mentioned above contain $\mathrm{N}$ - or C-terminal extensions/ domains in addition to the parvulin domain. Functional studies have shown that the parvulin domain of PpiD and the N-terminal domain of SurA both lack cis-trans isomerase activity, but possess chaperone activity [20, 28]. Due to their function, some parvulins are tightly linked to membranes: PrsA, a foldase for secreted proteins and essential for cell wall assembly in B. subtilis is connected with a lipid-anchor at an $\mathrm{N}$-terminal cysteine residue to the outer leaflet of the cell membrane $[22,29,30]$ and $\mathrm{PpiD}$, the periplasmic foldase of outer membrane proteins, is embedded in the lipid double-layer via an $\mathrm{N}$-terminal transmembrane helix [31]. The PrsA of L. monocytogenes is also attached to the membrane by a lipid-anchor and supports the correct folding of secreted proteins during infection and hence plays an important role for the virulence of the pathogen [32].

During the last decade, the number of sequenced and annotated archaeal genomes has increased, with some of them including parvulin homologue genes [33]. In contrast to the multi-domain parvulins described above, all identified archaeal parvulins consist of a single domain (sdPar) [34] and exhibit strong homologies to Par10 [27]. The first and only structurally characterized archaeal parvulin CsPinA [26] originates from the psychrophilic thaumarchaeote Cenarchaeum symbiosum, which lives as a symbiont of the marine sponge Axinella mexicana and therefore eludes pure cultivation. Hence, its expression has not been demonstrated in vivo and no further studies regarding the localization or the cellular role of CsPinA have been performed. Only the 3D structure of the archaeal representative $C s$ PinA has been characterized after expressing the protein recombinantly in E. coli. Furthermore, neither data of its catalytic activity nor its substrate specificity are available so far.

More recently, Könneke et al. [35] reported the isolation of the first thaumarchaeote into pure culture. Nitrosopumilus maritimus is $0.17-0.22 \mu \mathrm{m}$ in diameter and $0.5-0.9 \mu \mathrm{m}$ in length and grows chemoautotrophically by oxidizing ammonia to nitrite and by fixing carbon dioxide as a sole carbon source. Due to their ubiquity and high abundance, ammonia-oxidizing thaumarchaeotes have become recognized as major nitrifiers in a wide range of habitats [36]. Here, we provide novel insight into the cellular localization of the endogenous parvulin $N m$ Pin in $N$. maritimus and present a detailed high resolution structure. NmPin turned out to be a catalytically active prolyl-isomerase with a parvulin-type fold that is associated to the archaeal cell membrane.

\section{Results}

\section{$\mathrm{NmPin}$ is endogenously expressed and is a catalytically} active sdPar

In the genome of $N$. maritimus we identified an open reading frame, which encodes a putative 91 amino acid parvulin-like PPIase [34]. The putative parvulin, which we named NmPin, was recombinantly produced. The expected molecular mass and purity were confirmed by mass spectrometry (Fig. 1a), using $\alpha-N m$ Pin, an antibody that we generated to analyze the expression of endogenous NmPin by western blot under different osmotic conditions, as the salt concentration may be critical for the marine organism. For all conditions the blots showed a distinctive band at $\sim 10 \mathrm{kDa}$ indicating the expression of $N m$ Pin as a single domain parvulin (sdPar) also in vivo. At low salt concentrations, $N m$ Pin was found in the supernatant as well as in the membrane enriched pellet fraction of lysed N. maritimus. In contrast, high salt levels up to $500 \mathrm{mM} \mathrm{NaCl}$ disturbed the attachment to the membrane fraction and NmPin was predominantly found in the supernatant of $N$. maritimus lysates (Fig. 1b). Although this is, to our knowledge, the first description of an endogenous expression of an archaeal parvulin-type PPIase, the amounts of proteins were not sufficient for further biochemical and biophysical studies. Thus, we examined the catalytic activity of recombinant $N m$ Pin and performed a protease-coupled isomerase assay. In the presence of increasing concentrations of NmPin an accelerated interconversion of the peptide Suc-A-R-P-F- $p$ NA from cis to trans isoform was observed (Fig. 1c). We additionally assayed the substrate selectivity and specificity of $N m$ Pin by alternating the residue preceding the proline in the model substrate peptides. The fastest PPIase activity was observed for peptides carrying an arginine or a hydrophobic branched leucine at this position (Fig. 1d) with a rate constant for catalytic efficiency of $k_{\text {cat }} / K_{M}=6.1 \pm 1.3 \times 10^{5} \mathrm{M}^{-1} \mathrm{~s}^{-1}$ and $k_{\text {cat }} / K_{M}=5.7 \pm 1.5 \times 10^{5} \mathrm{M}^{-1} \mathrm{~s}^{-1}$, respectively. As expected from the high homology, the same substrate selectivity was observed for CsPinA. While the human Par14 shows the same substrate selectivity the bacterial EcPar10 from Escherichia coli prefers Leu to Phe and Ala [7]. In comparison to $N m$ Pin, the catalytic efficiency of $E c$ Par10 is 30 times higher $\left(\mathrm{K}_{\text {cat }} / \mathrm{K}_{\mathrm{M}}=1.69 \times 10^{7} \mathrm{M}^{-}\right.$ ${ }^{1} \mathrm{~s}^{-1}$ ), while the one for Par14 is about 600 times lower for a Leu-Pro model substrate. Similar to EcPar10 and Par14 but in contrast to the eukaryotic homologs ESS1 

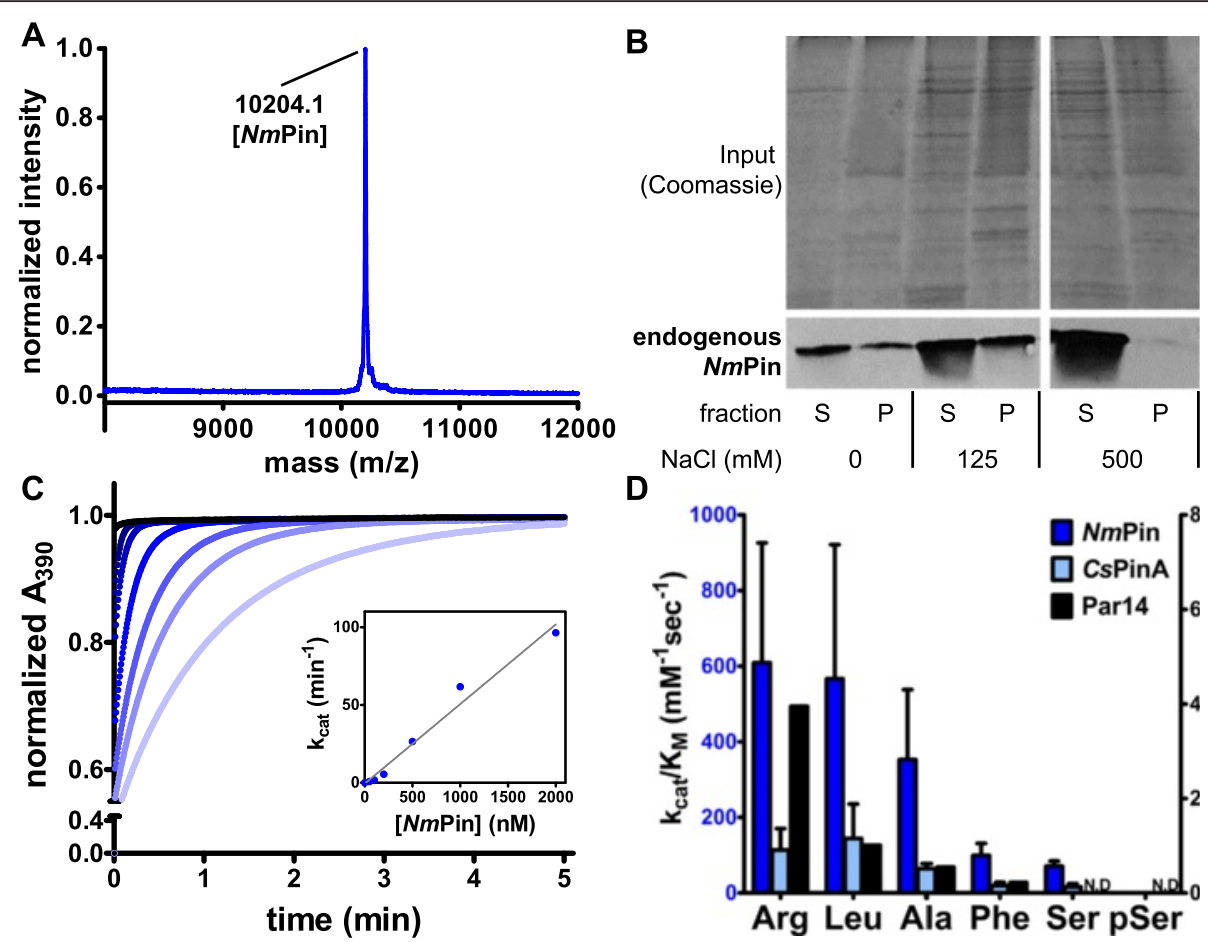

Fig. 1 Expression of endogenous protein and biochemical characterization of recombinant NmPin. a MALDI-TOF spectrum of recombinant NmPin. b Upper illustration, representative SDS-PAGE gel of N. maritimus cell lysates (Coomassie staining). Cells were treated with different salt concentrations before fractionation. Lower illustration, single Western blot experiment of endogenous NmPin using a-NmPin antibody. The corresponding fractions and salt conditions are annotated below. c Absorption curves revealing the time resolved cleavage of the peptide Suc-A-R-P-F-pNA in the presence of different NmPin concentrations in a protease-coupled isomerase assay. The amount of $\mathrm{NmPin}$ added to the reaction is indicated by a color gradient from $0 \mu \mathrm{M}$ (bright blue) to $2 \mu \mathrm{M}$ (dark blue). A steeper initial slope represents a faster isomerization. Insert: plot of catalytic constants $k_{c a t}$ derived from absorption curves by bi-exponential curve fits against the corresponding NmPin concentrations. $\mathbf{d}$ Diagram of $k_{c a t} / K_{M}$ values for various substrates comprising the scaffold Suc-A-X-P-F-pNA measured for NmPin (blue, left scale), CsPinA (light blue, left scale) and Par14 (black, right scale) [4]. The residue $X$ is specified on the $X$-axis of the diagram. Data are presented as means \pm standard deviation from six (two for CsPin) independent measurements with different enzyme concentrations

(C. albicans) and Pin1 (human) [12, 36-38], archaeal PPIases do not catalyze the isomerization of a phosphorylated serine motif (Fig. 1d).

\section{The solution structure of NmPin shows a parvulin-fold} and exhibits a novel lysine-rich patch

The three-dimensional structure of recombinant NmPin was determined by high resolution nuclear magnetic resonance (NMR) spectroscopy (Table 1, Fig. 2a).

The protein adopts the typical $\beta \alpha_{3} \beta \alpha \beta_{2}$ fold common for all parvulin proteins $[8,39]$ with short connecting loops and turns between the secondary structure elements (Fig. 2b). The closest homolog of NmPin is CsPinA from the phylogenetically related thaumarchaeote C. symbiosum with $78.4 \%$ sequence identity and a root mean square deviation (RMSD) of $1.28 \AA$ (PDB ID: 2RQS, Tab. 2).

However, regarding the folding and the special dimensions of the active site, the eukaryotic cis-/trans-isomerase Par14 from human (PDB ID: 3UI4, RMSD of $1.72 \AA$ ) shows the highest similarity to NmPin [8]. Hence, we have used the structure of Par14 to deduce and assign the catalytic tetrad of $N m$ Pin (C/D-H-H-T/S) [40]. It is built up by residues His10 and His87 (common dual histidine motif) [41], which are flanked by Asp42 and Ser82. To confirm the functionality of this derived tetrad, we mutated the two flanking residues to alanines, yielding the mutants $N m \operatorname{Pin}_{\mathrm{D} 42 \mathrm{~A}}$ and $N m \mathrm{Pin}_{\mathrm{S} 82 \mathrm{~A}}$ (Fig. 2c). The two mutant enzymes showed a significant decrease in catalysis rate when compared to the wildtype protein with residual activities of $0.7 \%$ and $3.5 \%$, respectively (Fig. $2 \mathrm{~d}$ ). As the circular dichroism (CD) spectra of the mutant proteins are comparable with the wild type spectrum (Fig. 2e), structural changes as the reason for the loss of PPIase activity can be excluded. To localize the substrate binding pocket on NmPin a ${ }^{1} \mathrm{H}^{15} \mathrm{~N}-\mathrm{HSQC}$-based NMR chemical shift perturbation experiment was performed using the -R-P- substrate peptide as a ligand. $\mathrm{HN}$ resonances comprising shift differences $\geq 0.04$ ppm (D42, K47, G53, M60, V61, A68, E83, Y86, I88) exclusively belong to residues of the active site or to surrounding amino acids (Fig. 2f). This strongly 
Table 1 NMR and refinement statistics for NmPin (residue 4-93)

\begin{tabular}{ll}
\hline NOE-based distance restraints & 352 \\
Intra-residual & 436 \\
Sequential & 318 \\
Medium range $(2 \leq|\mathrm{i}-\mathrm{j}| \leq 4)$ & 740 \\
Long range $(\mathrm{li}-\mathrm{j} \mid \geq 5)$ & 1846 \\
Total & 2 Distances, $3 \mathrm{vdW}$ \\
Violated & \\
Other restraints & 0 \\
D+ $\Psi$ dihedral restraints & 80 \\
Hydrogen bond restraints & \\
Coordinate precision ( $\AA$ ) & $0.30 \pm 0.04$ \\
Backbone & $0.80 \pm 0.03$ \\
All & \\
Whatcheck & $2.918 \pm 1.251$ \\
First-generation packing quality & $4.617 \pm 1.785$ \\
Second-generation packing quality & $0.886 \pm 0.227$ \\
Ramachandran plot appearance & $-3.471 \pm 0.486$ \\
$X^{1} / X^{2}$ rotamer normality & $1.647 \pm 0.186$ \\
Backbone conformation & \\
Ramachandran plot (\%) & 91.9 \\
Most favored regions & 7.0 \\
Generously allowed regions & 0.9 \\
Disallowed regions & 0.3 \\
\hline
\end{tabular}

suggests that substrates are bound and converted within the proposed catalytic groove. In addition, we have used a D42C mutant of $N m$ Pin to gain further information about the recognition of the residues $\mathrm{N}$-terminal to the proline in the substrate (Fig. 2g). The $N m \mathrm{Pin}_{\mathrm{D} 42 \mathrm{C}}$ has the same catalytic efficiency as wildtype NmPin (data not shown), but prefers short amino acids (Ala, Ser) compared to the wildtype (Arg, Leu). Interestingly, opposite to the catalytic cleft is a highly positively charged surface motif composed of eight lysines (K5, K7, K31, K34, K37, K47, K48, K90) (Fig. 2h). This prominent feature (K9, K11, K35, K38, K41, K51, R52, K94) is also found in CsPinA (Fig. 2i).

\section{$\mathrm{NmPin}$ binds to lipids and is located at the outer membrane side of $N$. maritimus}

The wide dimension, as well as the positive charge of the lysine-rich area of NmPin, might enable and promote an interaction between the protein and negatively charged lipids of the plasma membrane. The membrane of thaumarchaeotes mainly consists of the core lipid crenarchaeol, which is a glycerol dialkyl glycerol tetraether that occurs primarily as intact polar lipids, with phosphatidic, glycosidic or phosphoglycosidic negatively charged head groups [42-46]. We hypothesize that the interaction between $N m$ Pin and the membrane is mainly based on electrostatic interactions between the positive patch on the NmPin surface and negatively charged lipid head groups. Since the production of archaeal lipids in sufficient amounts for sedimentation assays was not feasible, we have used vesicles from bovine brain extract, mainly composed of negatively charged phosphatidylinositol and phosphatidylserine, as an intact polar lipid model to study the association of recombinant $N m$ Pin to polar lipids. Measuring the association of the protein to vesicles revealed that $N m$ Pin attached to the vesicle lipids and sedimented as a protein-lipid complex (Fig. 3a). With increasing lipid concentrations $(\geq 2 \mathrm{mg} / \mathrm{mL}$ ) only limited amounts of $N m$ Pin remained in solution. Due to the conserved positively charged patch CsPin can also be sedimented by lipid vesicles. To examine if the binding of both proteins originates from Coulomb interactions of the lysine-rich area, Lys7 and Lys34 of NmPin were mutated to glutamate (K7E/K34E) and thereby partially neutralized the central positive patch (Fig. $3 \mathrm{~b}$ ). In a lipid sedimentation assay, the interaction of the mutant with the lipids was impaired and vesicle association completely abolished (Fig. 3a). The same behavior was observed for the exclusive mutation of Lys7 (Fig. 3a, b), which is highly conserved among thaumarchaeotes [34]. Structural changes due to mutations could be excluded for both constructs by performing CD spectroscopy (Fig. 3c). To substantiate that NmPin associates with the membrane, we analyzed the localization of endogenous $N m$ Pin in $N$. maritimus using fluorescence microscopy. Cells were obtained with the previously described rod-shape morphology, when fixed by the addition of paraformaldehyde (PFA) [47, 48] (Fig. 4a). After immunochemistry, a membrane-associated localization pattern was observed for endogenously expressed $N m$ Pin in $N$. maritimus (Fig. 4b). As previously shown in numerous members of the archaea [49], N. maritimus very likely possesses a protein-based surface layer (S-layer) on the outer side of the membrane, which can be visualized with transmission electron microscopy (TEM) as an additional envelope surrounding the cell (Fig. 4c). Hence, to confirm the in vitro lipid binding properties of recombinant $\mathrm{NmPin}$ and to rule out an embedding into the surface layer, the S-layer was permeabilized by eliminating the PFA fixation step before harvesting the cells. Although the cells lost their rodshape and changed to a more spherical form with a diffuse cell membrane (Fig. 4d), endogenous $N m$ Pin was still detectable in concentrated areas at the surface of $N$. maritimus (Fig. 4e). In addition, the membrane association of $N m$ Pin was also confirmed by immunogold-labelling and subsequent TEM. Gold particles were localized in the circumference of permeabilized $N$. maritimus (Fig. 4f). Finally, N. maritimus was incubated in phosphate buffered saline (PBS), which on the one hand mimics low salt conditions for this marine archaea and leads 

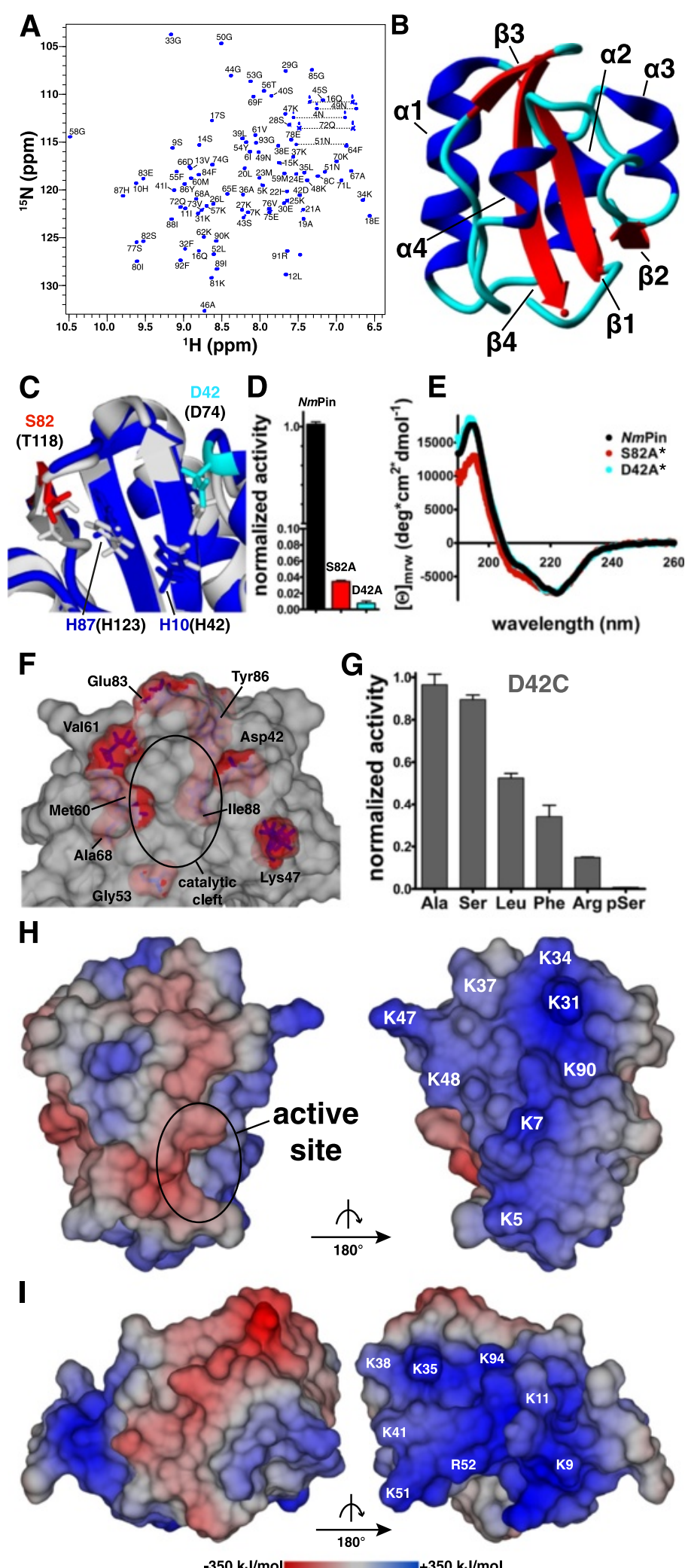

Fig. 2 (See legend on next page.) 
(See figure on previous page.)

Fig. 2 Solution structure and structural features of the parvulin NmPin from Nitrosopumilus maritimus. a Assigned ${ }^{1} \mathrm{H}-{ }^{15} \mathrm{~N}-\mathrm{HSQC}$ of recombinant $\mathrm{NmPin}$. Assignment was performed with CcpNmr analysis using HNCACB/CBCACONH spectra to trace the protein sequence chain. b Ribbon presentation of the tertiary structure of NmPin. The parvulin fold comprises a central four-stranded $\beta$-sheet (red) surrounded by four a-helices (blue), which are connected through short loops and turns (cyan). Secondary structure elements are annotated with Greek letters. c Superposition of the structures of NmPin (blue) and Par14 (grey, PDB ID: 3UI4) with the two histidines (dual histidine motive [41]) in the respective leading color. The outer residues of the catalytic tetrad of NmPin (D42 in cyan, S82 in red) and of hPar14 (D74 and T118 in brackets) [40] are indicated. $\mathbf{d}$ A diagram of normalized isomerase activity measured for wildtype NmPin (black column) and proteins comprising either S82A (red column) or D42A (cyan column) single residue mutations within the catalytic tetrad. The mutants S82A and D42A retain only a low residual activity of $3.5 \%$ and $0.7 \%$, respectively.

Data were recorded in duplicates and are presented as means \pm standard deviation. e Circular dichroism spectra of NmPin (black), NmPin $42 \mathrm{~A}$ (cyan) and $\mathrm{NmPin}_{\text {s82A }}$ (red) shown as mean residue ellipticity (mrw). *Datasets were normalized to the wildtype spectrum for better comparison of the three protein folds. $\mathbf{f}$ Surface representation of NmPin. Residues involved in substrate binding are mapped on the molecular surface (red, side chain atoms in purple sticks). Residues were derived from chemical shift perturbation analysis in a ${ }^{1} \mathrm{H}_{-}{ }^{15} \mathrm{~N}-\mathrm{SOFAST}-\mathrm{HMQC}$ titration experiment using Suc-A-R-P-F-pNA as a ligand. $\mathbf{g}$ Diagram of the normalized activity for various substrates comprising the scaffold Suc-A-X-P-F-pNA measured for NmPin $n_{D 42 C}$. The residue $X$ is specified on the $X$-axis of the diagram. Data are normalized to the substrate with the highest activity and are presented as means \pm standard deviation from two independent measurements with different enzyme concentrations. $\mathbf{h}$ and $\mathbf{i}$ Electrostatic potential of the molecular surface of NmPin and CsPin calculated with YASARA [83] using the Particle Mesh Ewald approach. The intensity of the surface potential is gradually colored from dark red (negative) over grey (neutral) to dark blue (positive) representing energy levels from -350 to $+350 \mathrm{~kJ} / \mathrm{mol}$. The active site of NmPin is encircled. The opposite sites of both NmPin as well as CsPin are defined by a positively charged lysine-rich patch as labelled, respectively.

to swelling and partial cell lysis, but on the other hand, the different phosphate concentrations might compete with NmPin for the binding to lipids. The fluorescence intensity, and hence the amount of endogenous NmPin, is decreased significantly under these conditions (Fig. 4g/h).

\section{Discussion}

\section{$\mathrm{NmPin}$ is a novel functional parvulin from a marine} Archaeon

In this study, we describe the endogenous expression of a novel archaeal parvulin and confirm its cellular occurrence as a single-domain protein. Our high resolution NMR structure of recombinant NmPin reveals a typical parvulin fold with all residues present to form a catalytically active site. $N m$ Pin, as well as its homologue CsPinA, show isomerase activity towards a series of tested model substrates (Fig. 1d). In contrast to eukaryotic Pin representatives but similar to other prokaryotic parvulins studied so far [50, 51], archaeal PPIases do not catalyze the isomerization of peptides containing a phosphorylated serine residue preceding the proline. However, protein phosphorylation as a regulatory mechanism is not generally excluded as numerous genomes of archaeal organisms contain open reading frames for potential protein kinases and protein phosphatases in homology to known eukaryotic proteins [52]. The inability of $N m$ Pin to isomerize phosphorylated peptides is structurally reflected by the absence of a phosphate-binding domain or phosphate-binding protein extension, which is present in all known phospho-specific prolyl isomerases such as the WW-domain in human Pin1 and ESS1 from C. albicans [37, 53-55] or a distinct four-amino acid insertion in several plant representatives [56]. The phosphate recognition by $N m$ Pin becomes also very unlikely considering the predominantly negative surface potential around the active site due to the exposed Glu83, which is also involved in substrate binding as shown by NMR chemical shift perturbation experiments (Fig. 2a). The substrate selectivity of $N m$ Pin for amino acids with long side chains (Arg, Leu) preceding the proline moiety is mainly determined by the catalytic site Asp42. Despite the structural differences between the sdPar NmPin and the $\mathrm{N}$-terminally extended human Par14, and the difference in

Table 2 Pairwise root mean square deviation (RMSD) of NmPin to parvulin homologs. RMSD values were calculated with YASARA using the alignment tool Mustang [84]

\begin{tabular}{|c|c|c|c|c|c|}
\hline Structure & PDB ID & $\operatorname{RMSD}(\mathrm{Ca})[\AA]$ & Aligned residues & \% Seq. identity & Citation \\
\hline CsPinA & $2 \mathrm{RQS}$ & 1.281 & 88 & 78.4 & [26] \\
\hline hPin1_PPlase & 1NMW & 1.301 & 89 & 44.9 & [85] \\
\hline SaPrsA_PPlase & $2 J Z \mathrm{~V}$ & 1.302 & 84 & 54.8 & [25] \\
\hline TbPin1_PPlase & $2\llcorner J 4$ & 1.382 & 89 & 38.2 & [86] \\
\hline hPar14_PPlase & $3 \cup 14$ & 1.715 & 86 & 46.5 & [40] \\
\hline EcPpiD_PPlase & 2KGJ & 1.732 & 80 & 30.0 & [20] \\
\hline AtPin 1 & $1 \mathrm{~J} 6 \mathrm{Y}$ & 1.905 & 86 & 39.5 & [42] \\
\hline EcPar10 & 1JNT & 2.267 & 84 & 41.7 & [27] \\
\hline
\end{tabular}




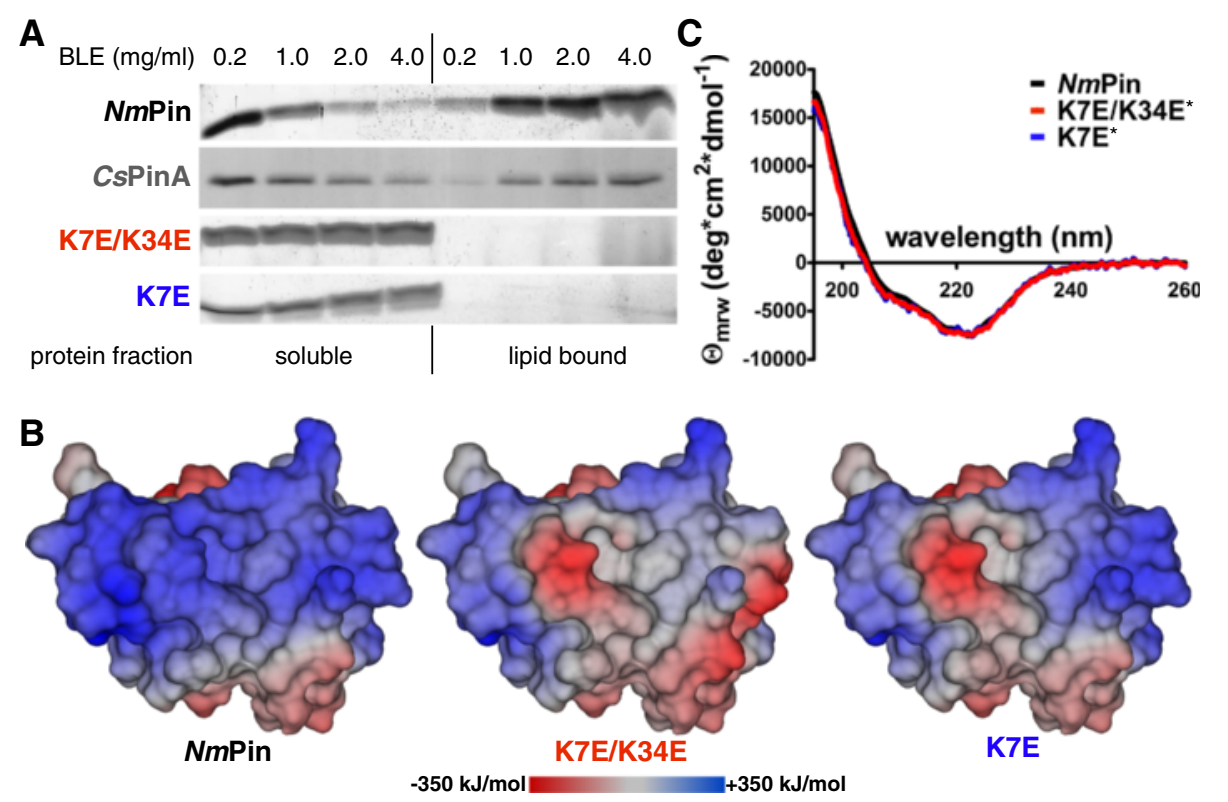

Fig. 3 Lipid binding ability of recombinant NmPin. a Coomassie stained SDS-PAGE of $15 \mu M$ NmPin (wildtype, black; NmPin KFE/K34E, red; NmPin ${ }_{\text {K7E, }}$ blue) as well as $15 \mu \mathrm{M}$ CSPinA (grey) in the presence of different concentrations of brain lipid extract (BLE). Layers resemble the amount of protein found in either the soluble or the lipid bound fraction after sedimentation (lipid sedimentation assay). The amounts of BLE are annotated above and the corresponding protein fractions are indicated below. b Electrostatic surface potential of wildtype NmPin (black), NmPin K7E/K34E (red) and $\mathrm{NMPin}_{\mathrm{K} 7 \mathrm{E}}$ (blue) calculated with Particle Mesh Ewald approach (PME). The intensity of the potential is indicated by a color gradient from dark red (negative), over grey (neutral), to dark blue (positive) ranging from -350 to $+350 \mathrm{~kJ} / \mathrm{mol}$. The mutants K7E/K34E and K7E were modeled using residue swaps in YASARA prior to calculation of the electrostatic potential. c Circular dichroism spectra of NmPin (black), NmPin K7E (blue) and NmPin K7E/K34E (red) shown as mean residue ellipticity (mrw). *Datasets were normalized to the wildtype spectrum for better comparison of the three protein folds

the catalytic efficiency $\left(\operatorname{Par} 14: k_{c a t} / K_{M}=1.01 \times 10^{3} \mathrm{M}^{-1} \mathrm{~s}^{-1}\right.$ [57], NmPin: $k_{\text {cat }} / K_{M}=5.66 \times 10^{5} \mathrm{M}^{-1} \mathrm{~s}^{-1}$ for Suc-A-L-PF-pNA), their substrate selectivity is nearly identical. This observation supports recent studies, where the TACK superphylum, including the Thaumarchaeota, were put in a phylogenetic sister relationship with Eukaryotes [58-61]. Although NmPin and Par14 seem to have the same substrate selectivity, their cellular localization seem to determine their different function in the cell since NmPin is important for the folding of extracellular proteins while the human Par14 is involved in signal transduction [62] and the maturation of ribosomal RNA [63].

\section{The surface layer provides $N$. maritimus cells with a rod-shaped structure}

The vast majority of archaea possesses a single membrane and most of these membranes are covered by a protein layer, which consists of a single protein species often modified by glycosylation [49]. Our TEM data clearly indicate that the rod-shaped cells of $N$. maritimus are also enveloped by a surface layer (S-layer). The precise composition of this S-layer is unknown. However, upon stress, either mechanical (centrifugation) or osmotic (salt concentration), the cell shape is altered to a spheroidal form, which is accompanied by a ruptured S-layer (Fig 4c, f [35]). Additionally, some cells eject parts of their cytoplasm due to damage (Fig. 4h). Only a small number of cells are able to avoid the stress and remain intact. The S-layer maintains the cellular shape of the prokaryote. However, the exact physiological role of the S-layer in $N$. maritimus under natural conditions needs to be investigated. It is important for the shape of the organism but may also provide protection against natural enemies and viruses.

\section{NmPin is located on the outer membrane surface}

The cytoplasmic membrane of $N$. maritimus consist of intact polar lipids with negatively charged phosphatidic, glycosidic or phosphoglycosidic head groups [43-45], which present an interface suitable for binding to the lysine-rich patch provided by NmPin. The use of eukaryotic lipids as a model system for our lipid sedimentation assays strengthens the pure electrostatic character of the NmPinlipid interaction since no further anchoring seems to be required. This type of attaching PPIases to a membrane simply by electrostatic interactions might be a general feature of archaeal parvulins since the patch is also conserved in CsPinA from C. symbiosum. In addition, the flat shape of the lysine cluster provides ideal conditions for an electrostatic membrane interaction, in contrast to DNA binding proteins, which mostly possess basic patches with significant curvature $[64,65]$. A mutation of the highly conserved residue Lys7 [35] to Glu7 hampers binding of NmPin to 

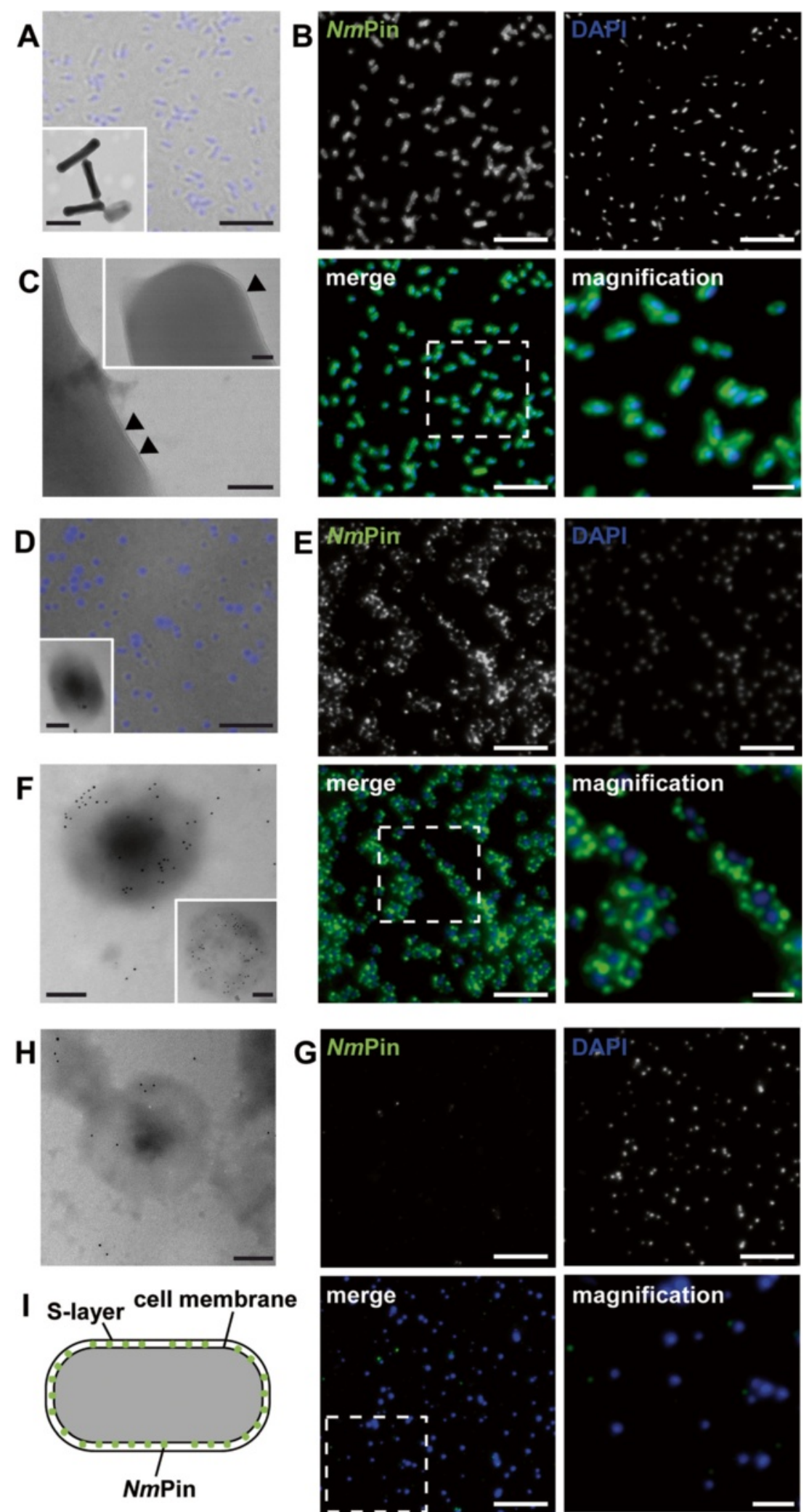

magnification

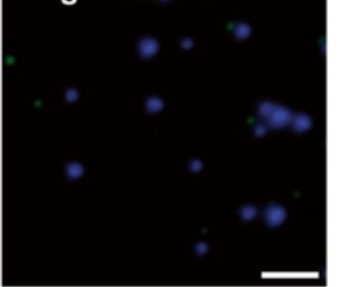

Fig. 4 (See legend on next page.) 
(See figure on previous page.)

Fig. 4 Localization of endogenous NmPin in N. maritimus observed by microscopy. a Overlay of brightfield (grey) and fluorescence (blue, DAPI stain) microscopy images (bar: 5 um). Cells exhibit a normal rod-shaped form after paraformaldehyde (PFA) fixation before harvesting by centrifugation as observed by transmission electron microscopy (TEM) (insert, bar: $500 \mathrm{~nm}$ ). b Fluorescence microscopy of PFA-fixed N. maritimus (bars: 5 m). Top left, immuno-staining of endogenous NmPin with Alexa488. Top right, DAPI staining of DNA. Bottom left, overlay of NmPin and DAPI stained cells. The square indicates the area of magnification. Bottom right, magnification of NmPin stained cells show a localization in the cell envelope (bar: $2 \mu \mathrm{m}$ ). c Detailed TEM microscopy images of PFA-fixed N. maritimus cells show a surface layer (S-layer) enframing the cytoplasmic membrane (arrowheads, bar: $50 \mathrm{~nm}$, bar insert: $20 \mathrm{~nm}$ ). d Overlay of brightfield (grey) and DAPI stain (blue) images of N. maritimus without PFA fixation before harvesting (bar: $5 \mu \mathrm{m}$ ). The insert shows a TEM image confirming a change in cell shape to a more spheroidal form with a very diffuse membrane structure (bar: $100 \mathrm{~nm}$ ). e Fluorescence microscopy images of $\mathrm{N}$. maritimus without PFA fixation before harvesting (bars: 5 um). Top left, NmPin fluorescence-staining with Alexa488. Top right, DAPI stain. Bottom left, overlay of NmPin and DAPI stained cells. The square indicates the area of magnification. Bottom right image shows a magnification of the NmPin stain with a less uniform localization in the cell envelope (bar: $2 \mu \mathrm{m}) . \mathbf{f}$ TEM microscopy picture of Immunogold-labelled NmPin in N. maritimus without PFA treatment (bars: $100 \mathrm{~nm}$ ). Black spots representing NmPin are concentrated in the outer diffuse membrane area of $\mathrm{N}$. maritimus cells. $\mathbf{g}$ Fluorescence microscopy images of $\mathrm{N}$. maritimus incubated in low salt conditions (phosphate buffered saline; PBS) (bars: $5 \mu \mathrm{m}$ ). Top left, picture of immuno-stained NmPin with Alexa488, showing a significant decrease of fluorescence intensity in comparison to marine salt conditions. Top right, DAPI stained cells. Bottom left, overlay of DAPI and NmPin stained cells. The square indicates the area of magnification. Bottom right, the magnification of NmPin stain confirms the signal intensity loss (bar: $2 \mu \mathrm{m}) \cdot \mathbf{h}$ TEM microscopy image of Immunogold-labelled NmPin in N. maritimus after incubation in PBS (bar: $100 \mathrm{~nm}$ ). Black spots representing NmPin are localized arbitrarily and show a detachment of NmPin from the cell envelope. i Schematic presentation of NmPin localization in N. maritimus

lipids. For endogenously expressed $\mathrm{NmPin}$, no integral lipid anchors or transmembrane helices for proper membrane binding were found. This is in contrast to the two known membrane-bound bacterial parvulins, where PrsA of $B$. subtilis is connected to the outer leaflet of the cell membrane with a lipid-anchor attached at an $\mathrm{N}$-terminal cysteine residue $[22,29,30]$ and $\mathrm{PpiD}$ of $E$. coli, which is embedded in the double-layer via an N-terminal transmembrane helix [31]. However, in human cells, several examples of peripheral membrane proteins are found where a nonspecific electrostatic interaction between a cluster of basic residues of the protein and acidic phospholipids in the membrane is required for activity and regulation [64]. In $N$. maritimus cells with an intact membrane, $N m$ Pin is observed and highly abundant on the surface (Fig. 4b, g). In contrast, the amount of NmPin in cells treated with PBS is significantly reduced. The hypoosmotic stress leads to a complete removal of the S-layer as well as a swelling of $N$. maritimus and, concomitantly, a different surface curvature which can interfere with lipid-NmPin complex formation. The multivalent negative phosphate ion, which is a strong competitor for the interaction with charged lipids [66], may have an additional effect. Both effects in combination could lead to the release of $N m$ Pin from the membrane under low salt conditions. Therefore, we assume that $N m$ Pin is located in the 'quasi-periplasmic space' between the membrane and the S-layer [67, 68] (Fig. 4i). Several ways for the secretion of folded and unfolded proteins in archaea have been reported. For example, the general secretion (Sec) pathway or the Twin arginine translocase (Tat) pathway that might also be responsible for the translocation of $N m$ Pin $[69,70]$.

To investigate a potential general role of a lysine-patch for parvulins we calculated the electrostatic potential of the molecular surface of other homologues of NmPin (Table 2, Fig. 5). Interestingly, the positively charged lysine-patch seems to be conserved only in archaeal parvulins (NmPin, CsPin) while bacteria seem to use transmembrane helices or lipid anchors to attach their parvulins to membranes (EcPpiD, SaPrsA). No membrane attachment module (transmembrane helix, lipid anchor or lysine patch) can be found in higher eukaryotes. A membrane anchor or a transmembrane domain is perhaps a more advanced and safer way for organisms to attach a protein to a membrane and the membrane binding by a positively patch might be lost during evolution. To verify a conservation of the lysine-patch in Archaea we have done a sequence alignment of all archaeal NmPin homologues available from the NCBI database (Additional file 1). When comparing the positions of lysines contributing to the positively charged patch in CsPin and NmPin all Thaumarchaeota, Crenarchaeota and ARMANs may show a similar lysine-patch on their surface. However, parvulins from Euryarchaeota show only a weak conservation, which may lead to a lower affinity or even no binding to the membrane, while bacterial (EcPar10) and eukaryotic parvulins (Par14, hPin1) lack this prominent feature completely, which is in line with electrostatic potential of the molecular surface of some representatives (Fig. 5). Hence, the lysine patch might be a general feature of parvulins from organisms of the TACK phylum rather than all Archaea.

\section{Functional role of $\mathrm{NmPin}$}

We monitored the localization of NmPin under different osmotic conditions and observed a strong accumulation of the isomerase next to the cell membrane under marine-like salt conditions (Fig. 4b, e). Under low salt stress, NmPin levels are significantly reduced (Fig. 4g), which contradicts an involvement in stress-related pathways and suggests a similar cellular role of $\mathrm{NmPin}$ as observed for the PPIases PrsA [23], PpiD [31] and SurA 


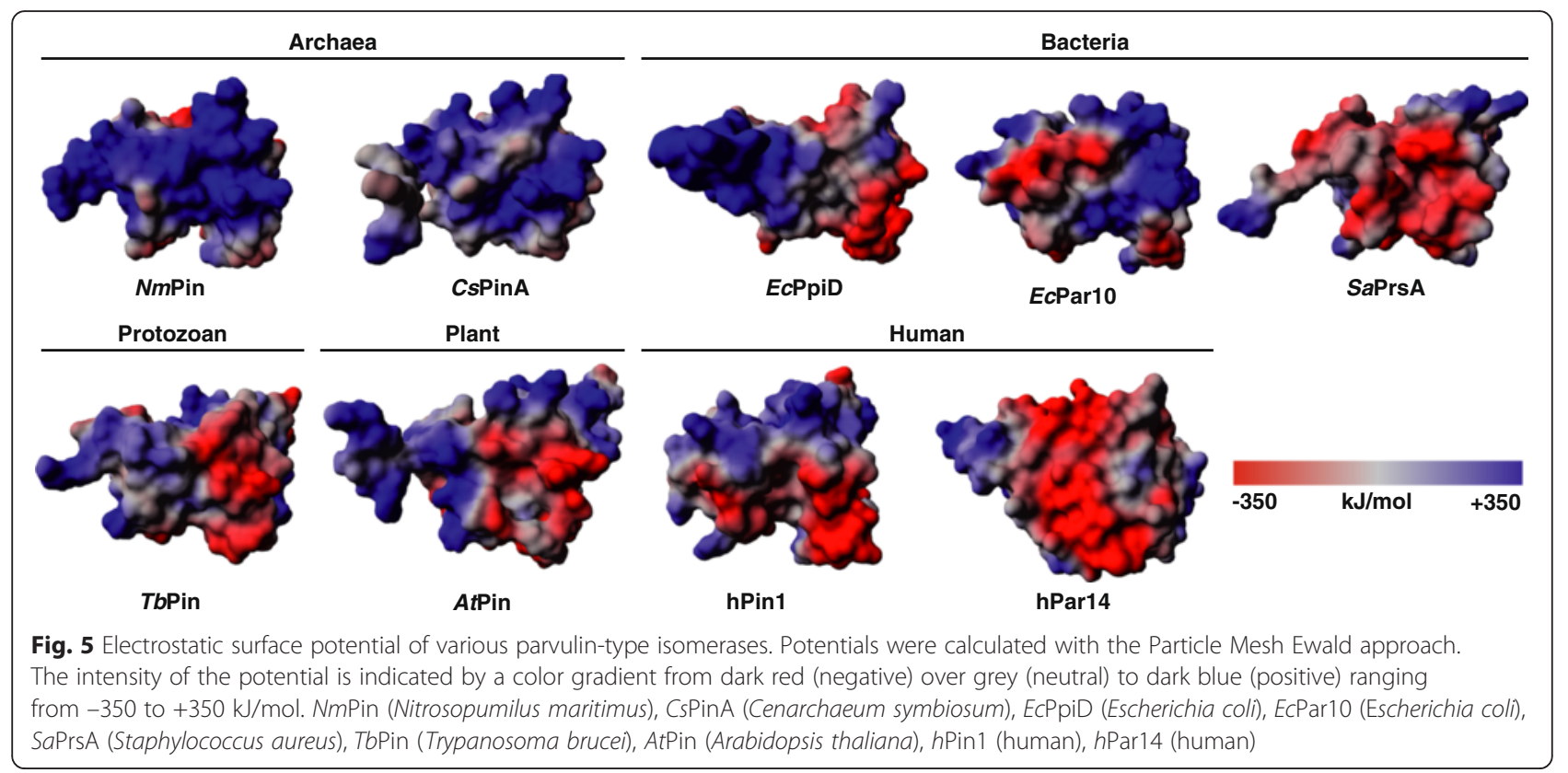

[19] in bacteria. The latter are located at the membrane and are involved in the maturation of extracellular, periplasmic and outer membrane proteins. We therefore assume $N m$ Pin to be involved in the folding of S-layer proteins and in maintaining the correct structure of the cell envelope. However, we do not yet have any information about the S-layer protein of $N$. maritimus. Nevertheless, our hypothesis of an pseudo-periplasmic space located PPIase is supported by the fact that the S-layer glycoprotein complex (tetrabrachion) of the related Crenachaeote Staphylothermus marinus contains a unique proline residue inside a V-I-P-K-F motif which separates the right-handed and left-handed supercoil parts [71, 72]. Obviously, the cis-/trans-conformation of the proline affects the structure of the glycoprotein complex and thereby influences the structure of the whole S-layer. Indeed, we could find a peptidylprolyl isomerase in Staphylothermus marinus with a high proportion of lysines (12.0 \%) similar to NmPin (16.1\%) pointing towards a potential lysine patch for membrane binding whereby no transmembrane helices could be predicted. This indicates the importance of foldingassisting PPIases such as NmPin at the outside of the cell membrane for archaeal organisms.

\section{Conclusion}

In this study, we determined the solution structure of the parvulin NmPin from the ubiquitous and ecological relevant thaumarchaeote $N$. maritimus. NmPin represents the first prolyl isomerase of the domain Archaea whose parvulin-like activity as well as membrane-associated location in vivo were characterized. Its structure revealed a lysine-rich patch, which was identified as a membrane- binding interface in vitro. In vivo $\mathrm{NmPin}$ is located at the outer surface of the membrane. The endogenous cellular expression level of the protein and its uniform distribution is highest in the presence of an intact cell envelope, precisely between the membrane and S-layer. Membrane association has been previously reported for multi-domain parvulins in bacteria $[18,21,22]$ as well as in eukaryotes [73]. For $N m$ Pin we present a novel type of membrane association of a single-domain parvulin without any need for anchoring modifications or transmembrane domains, which might be a more general feature of archaeal parvulins since the same kind of membrane interaction was observed for CsPinA. Considering recent studies, which suggest that the archaeal ancestors of eukaryotes are affiliated with the TACK superphylum, including the Thaumarchaeotes [58-61], NmPin likely represents a highly original member of the parvulin family. This assumption is supported by our results, showing that the NmPin folding topology and substrate selectivity are still conserved in the human Par14 protein $[8,57]$.

\section{Methods}

\section{Cloning and mutagenesis}

The nmpin gene was PCR-amplified with oligonucleotides forward (5'-CATTCGGGCCCTCAAACAAAATCAAATGTTCACAC-3') and reverse (5'-TGCAGGGAT CCTTATCCGAATCTCTTGATAATATG-3') (Metabion) using genomic DNA of $N$. maritimus as a template. The resulting fragment containing the restriction sites for ApaI and BamHI (NEB, Fermentas) was cloned into a modified pET-41b(+) (Addgene) vector as described elsewhere [74]. Mutants of nmpin were designed by site-directed mutagenesis using the QuikChange ${ }^{\mathrm{ma}}$ Lightning or the Q5 site- 
directed mutagenesis kit (Stratagene, NEB) and confirmed by Sanger sequencing (GATC GmbH).

\section{Protein expression and purification}

For protein production, plasmids were transformed into E. coli BL21(TL3)T1r (Sigma). Unlabeled protein was produced in $1 \mathrm{~L}$ of $2 \times \mathrm{YT}$ medium, grown to an optical density at $600 \mathrm{~nm}\left(\mathrm{OD}_{600}\right)$ of 0.8 at $37{ }^{\circ} \mathrm{C}$. For isotopically-labelled protein, cells of a culture of $1 \mathrm{~L}$ in LB medium $\left(\mathrm{OD}_{600}\right.$ of 0.8$)$ were transferred to $4 \mathrm{~L} \mathrm{M9}$ minimal medium supplemented with $1 \mathrm{~g} / \mathrm{L}\left[{ }^{15} \mathrm{~N}\right]$ ammonium chloride and, if required, $4 \mathrm{~g} / \mathrm{L}\left[{ }^{13} \mathrm{C}\right]$ glucose and further grown to an $\mathrm{OD}_{600}$ of 1.0. Subsequently, protein expression was induced by addition of $0.2 \mathrm{mM}$ IPTG and incubated overnight at $25{ }^{\circ} \mathrm{C}$ prior to centrifugation $(3700 \times g$, $20 \mathrm{~min}, 4^{\circ} \mathrm{C}$ ). Cell lysis of the resuspended pellet in PBS at $\mathrm{pH} 8.0$ was performed by sonification (Bandelin Sonopuls). Cell debris were removed by ultracentrifugation $\left(95,800 \times g, 4{ }^{\circ} \mathrm{C}, 60 \mathrm{~min}\right)$ and the supernatant was applied to a GSH-sepharose column (GE Healthcare) and eluted with $10 \mathrm{mM}$ glutathione. The GST-tag was cleaved off by PreScission protease and the resulting $N m$ Pin protein purified by size exclusion chromatography (SEC) on a Superdex 75PG 26/600 (GE Healthcare) in $50 \mathrm{mM}$ Tris and $150 \mathrm{mM} \mathrm{NaCl}$ at $\mathrm{pH}$ 8.0. Finally, the protein was dialyzed against buffers as indicated.

\section{MALDI-TOF}

Recombinant NmPin $(10 \mu \mathrm{g})$ was desalted with C18-tips (Supel-Tips C18, Supelco), eluted with $2 \mu \mathrm{L}$ of $50 \%$ (v/ v) acetonitrile $/ 0.1 \%(\mathrm{v} / \mathrm{v})$ trifluoroacetic acid and acidified with an equal volume of $2.0 \%(\mathrm{v} / \mathrm{v})$ trifluoroacetic acid. The sample was embedded in a saturated dihydroxyacetophenone matrix in ethanol with $25 \%(\mathrm{v} / \mathrm{v})$ aqueous ammonium citrate dibasic solution $(18 \mathrm{mg} / \mathrm{mL})$. Analysis was performed using an autoflex speed (Bruker) operated in a positive ionization and reflector mode. Spectra were recorded with flexcontrol and the dataset processed with flexanalysis (Bruker).

\section{N. maritimus cultivation and harvesting}

N. maritimus cultivation was performed as described previously $[35,47,75]$ in synthetic crenarchaeota media (SCM) with a starting concentration of $1 \mathrm{mM}$ ammonium chloride as an energy source. Batches of $5 \mathrm{~L}$ were inoculated with $5 \%(\mathrm{v} / \mathrm{v})$ culture of $N$. maritimus, incubated at $29^{\circ} \mathrm{C}$ in the dark without stirring and growth was monitored via nitrite concentration. Cells were harvested by centrifugation $\left(4800 \times g, 25{ }^{\circ} \mathrm{C}, 60 \mathrm{~min}\right)$ and pellets resuspended in PBS at $\mathrm{pH}$ 8.0.

\section{Western blot}

$\alpha-N m$ Pin antibody for detection of the endogenous protein was produced in rabbits with recombinant $N m$ Pin from E. coli as the antigen (Eurogentec). The final bleed was affinity purified against recombinant NmPin. For western blot analysis cells were washed in cold PBS at $\mathrm{pH} 8.0$ with variable salt concentrations as indicated, supplemented with a protease inhibitor cocktail (Roche mini) and lysed by sonification $(5 \times 15 \mathrm{~s}$ at $60 \%$ intensity, Sonopuls, Bandelin) prior to ultracentrifugation at $100,000 \times g, 4{ }^{\circ} \mathrm{C}$ for $50 \mathrm{~min}$. The supernatant was removed and the pellet resuspended in the same volume of PBS. Samples were subjected to SDS-PAGE and transferred by a semi-dry blot to a nitrocellulose membrane (30 min, $80 \mathrm{~mA})$. Blocking of the membrane was done in PBST150 (PBS, pH 8.0, $150 \mathrm{mM} \mathrm{NaCl}, 0.1 \%$ (v/v) Tween20) with $3 \%$ milk powder at $4{ }^{\circ} \mathrm{C}$ overnight; 1:1000 diluted $\alpha-N m$ Pin was incubated in the same buffer for $3 \mathrm{~h}$ at room temperature (RT). Washing of the membrane was done with one step PBST500 (PBS, $\mathrm{pH}$ 8.0, $500 \mathrm{mM} \mathrm{NaCl}, 0.1 \%(\mathrm{v} / \mathrm{v})$ Tween20) followed by two steps with PBST150, each $15 \mathrm{~min}$ at RT under shaking. Incubation of HRP-coupled $\alpha$-rabbit IgG secondary antibody (Sigma) was done in a 1:2000 dilution in PBST150 with $3 \%$ milk powder for $30 \mathrm{~min}$ at RT. The membrane was washed as before and subjected to chemoluminescent detection with SuperSignal West Femto Kit (Thermo) on a CL-XPosure film (Thermo).

\section{PPlase activity}

Catalytic activity of NmPin was measured using a conformer-specific protease coupled assay as described previously $[5,76]$. The chromogenic peptide substrates, following the scaffold Suc-Ala-Xaa-Pro-Phe-paranitroaniline $(p \mathrm{NA})$, were pre-incubated overnight in $0.5 \mathrm{M}$ $\mathrm{LiCl}$ in 2,2,2-trifluoroethanol at a concentration of $15 \mathrm{mM}$. $\alpha$-chymotrypsin (35 $\mu \mathrm{M}$; Sigma) was equilibrated with variable concentrations of $\mathrm{NmPin}$ for $5 \mathrm{~min}$ in PBS buffer at pH 6.8 at $10{ }^{\circ} \mathrm{C}$. Subsequently, the assay was started by addition of $75 \mu \mathrm{M}$ peptide and the reaction was spectrophotometrically monitored via $p \mathrm{NA}$ cleavage at $390 \mathrm{~nm}$. For each substrate, the cis-content of the peptide and the reaction rate constant of chymotrypsin were determined on the basis of the uncatalyzed digestion. Using these constants the observed curves were fitted globally to a bi-exponential reaction equation with GraphPad Prism 5.04. The $k_{c a t} / K_{M}$ was obtained from conditions with linear reaction rate to PPIase concentration correlation by using the following equation: $k_{\text {cat }} / K_{M}=\left(\mathrm{k}_{\text {obs }}-\mathrm{k}_{\text {uncat }}\right) /[$ [PPIase].

\section{NMR spectroscopy and resonance assignment}

Spectra were recorded on a Bruker Ultrashield $700 \mathrm{MHz}$ spectrometer equipped with a cryoprobe unit at $300 \mathrm{~K}$. For sample preparation, $1 \mathrm{mM} \mathrm{NmPin}$ was dissolved in $600 \mu \mathrm{L}$ of $50 \mathrm{mM} \mathrm{KP}$ i buffer, $\mathrm{pH}$ 6.5, $10 \% / 90 \%(\mathrm{v} / \mathrm{v})$ $\mathrm{D}_{2} \mathrm{O} / \mathrm{H}_{2} \mathrm{O}$ or $100 \% \mathrm{D}_{2} \mathrm{O}$ containing $0.02 \%(w / v) \mathrm{NaN}_{3}$ 
and $50 \mu \mathrm{M}$ DSS as calibration standard. Spectra were usually recorded using pulse sequences from the Bruker standard library (except ${ }^{1} \mathrm{H}_{-}{ }^{15} \mathrm{~N}-\mathrm{HSQC}-\mathrm{NOESY}$ ). A set of a ${ }^{1} \mathrm{H}^{15} \mathrm{~N}-\mathrm{HSQC}$, an HNCACB and a CBCACONH spectrum was sufficient to trace the chain of the protein sequence and to assign $\mathrm{H}_{\mathrm{N}}, \mathrm{N}_{\mathrm{H}}, \mathrm{C} \alpha$ and $\mathrm{C} \beta$ atoms of $N m$ Pin to their respective frequencies in the spectrum. The assignment of carbon atoms was completed using $\mathrm{HCCH}$-TOCSY and -COSY spectra and the ${ }^{1} \mathrm{H}$ assignment by ${ }^{1} \mathrm{H}_{-}{ }^{13} \mathrm{C}$ - and ${ }^{1} \mathrm{H}_{-}{ }^{15} \mathrm{~N}-\mathrm{HSQC}$-TOCSY spectra. Aromatic hydrogen atoms were assigned by $2 \mathrm{D}$ spectra (TOCSY, COSY, NOESY in $\mathrm{H}_{2} \mathrm{O}$ and $\mathrm{D}_{2} \mathrm{O}$ ). NOESY distance constraints were retrieved from 2D-NOESY and $3 \mathrm{D}{ }^{1} \mathrm{H}_{-}{ }^{15} \mathrm{~N}-\mathrm{HSQC}-\mathrm{NOESY}$ spectra. Processing and evaluation of spectra was performed with Topspin 3.0 (Bruker), assignment was done with the CcpNmrAnalysis 2.3.1 software package [77].

\section{Structure calculation}

NOE restraints were identified and transformed into distance constraints using the automated standard protocol of Cyana. For each hydrogen bond, retrieved from a series of ${ }^{1} \mathrm{H}_{-}{ }^{15} \mathrm{~N}-\mathrm{HSQC}$ spectra after lyophilizing NmPin and dissolving it in $100 \% \mathrm{D}_{2} \mathrm{O}$, two lower limit constraints were set for the distances from $\mathrm{N}$ to $\mathrm{O}$ and from $\mathrm{HN}$ to O. The structure of NmPin was calculated using Cyana 3.0 [78]. Owing to the high sequence identity (78.4 \%) of NmPin to CsPinA (PDB ID: 2RQS) a homology model was calculated using the software YASARA (Nova forcefield) and set as guide structure for a first cycle of calculation. Water refinement was performed with the software package YASARA using the structure module and the YASARA Nova forcefield [79]. Structural coordinates and NMR shift data were deposited in the RCSB databank (entry ID: 2MO8) and in the BMRB databank (entry ID: 18801), respectively.

\section{Chemical shift perturbation analysis}

To a $200 \mu \mathrm{M}$ sample of ${ }^{15} \mathrm{~N}$-labelled $N m$ Pin in $50 \mathrm{mM}$ $\mathrm{KP}_{\mathrm{i}}, \mathrm{pH}$ 6.5, the peptide Suc-A-R-P-F-pNA in the same buffer was added stepwise to a final concentration of $15 \mathrm{mM}$. For each step, a ${ }^{1} \mathrm{H}_{-}{ }^{15} \mathrm{~N}$ - SOFAST-HMQC spectrum at $25{ }^{\circ} \mathrm{C}$ was recorded. All residues exhibiting chemical shifts $\geq 0.04 \mathrm{ppm}$ were used to map the substrate binding interface on the surface of the NmPin structure using YASARA [36].

\section{Lipid sedimentation assays}

Lipid-binding of $N m \mathrm{Pin}_{\mathrm{wt}}, N m \mathrm{Pin}_{\mathrm{K} 7 \mathrm{E} / \mathrm{K} 34 \mathrm{E}}$ and $N m \mathrm{Pin}_{\mathrm{K} 7 \mathrm{E}}$ was carried out as described previously with modifications [80, 81]. Brain lipid extracts from bovine (Folch fraction I, Sigma) were resuspended in HEPES buffer (20 mM HEPES, $150 \mathrm{mM} \mathrm{NaCl}, \mathrm{pH}$ 7.4) to a concentration of $5 \mathrm{mg} / \mathrm{mL}$ under continuous stirring. The protein samples $(15 \mu \mathrm{M})$ were incubated with varying liposome concentrations for $15 \mathrm{~min}$ at $37^{\circ} \mathrm{C}$ and $350 \mathrm{rpm}$ in a total volume of $40 \mu \mathrm{L}$ and subsequently centrifuged (50 min, $100,000 \times g, 4{ }^{\circ} \mathrm{C}$ ). The supernatant was removed and the pellet resuspended in the equivalent volume HEPES buffer prior to analysis by SDS-PAGE.

\section{CD spectroscopy}

$\mathrm{CD}$ spectra were measured in $0.1 \mathrm{~cm}$ cuvettes with $0.15 \mathrm{mg} / \mathrm{mL}$ protein in $50 \mathrm{mM} \mathrm{NaP}, \mathrm{pH} 7.4$ at $20{ }^{\circ} \mathrm{C}$ as a sum of 50 single spectra with a Jasco J-710 spectropolarimeter (Jasco, Gross-Umstadt). A buffer baseline was subtracted from all datasets, units were converted to mean residue ellipticity and the mutant spectra normalized to the wildtype spectrum.

\section{Fluorescence microscopy}

For localization of endogenous $\mathrm{NmPin}, 10 \mathrm{~mL}$. maritimus suspension in SCM medium, with or without addition of $4 \%$ PFA, were centrifuged for $60 \mathrm{~min}$ at $4800 \times g$ at $25^{\circ} \mathrm{C}$. The supernatant was discarded and the pellet resuspended in $200 \mu \mathrm{L} \mathrm{SCM}$ medium or PBS as indicated. Cells were incubated for $1 \mathrm{~h}$ at $29^{\circ} \mathrm{C}$ for attachment to poly-lysine coated cover slips. Fixation was done with ice-cold $4 \%$ PFA in PBS for $15 \mathrm{~min}$ at RT. For permeabilization, the PFA was supplemented with $0.1 \%$ Triton. Five washing steps (each $3 \mathrm{~min}$ ) with PBS were performed to stop the cross-link reaction. Blocking was done with $5 \%$ goat serum in PBST (PBS, $0.1 \%(\mathrm{v} / \mathrm{v})$ Tween20) for $1 \mathrm{~h}$ at RT. $\alpha$-NmPin antibody (1:50, rabbit) was incubated in $3 \%$ goat serum/PBST overnight at $4{ }^{\circ} \mathrm{C}$ followed by four washing steps with PBST (each $3 \mathrm{~min}$ ). Alexa488-coupled secondary $\alpha$-rabbit IgG antibody from goat (Invitrogen) was diluted in $3 \%$ goat serum/PBST $(2 \mu \mathrm{g} / \mathrm{mL})$ and incubated for $1 \mathrm{~h}$ at $\mathrm{RT}$ in the dark followed by four washing steps with PBST (each $3 \mathrm{~min}$ ). DNA was stained with DAPI contained in the mounting medium (Vectashield, Vector Laboratories). Pictures were taken with a Zeiss Imager M2 with metal halide light source and the corresponding filter set (Alexa488: $495 \mathrm{~nm} / 517 \mathrm{~nm}$, exposure time: $500 \mathrm{~ms}$, DAPI: $395 \mathrm{~nm} /$ $461 \mathrm{~nm}$, exposure time: $200 \mathrm{~ns}$ ). Data processing was done with ZEN 2012 SP blue edition.

\section{TEM}

Sample preparation for TEM microscopy was modified as described previously [82]; $10 \mathrm{~mL} N$. maritimus suspension in SCM medium, with or without addition of $4 \%$ PFA, were centrifuged for $60 \mathrm{~min}$ at $4800 \times g$ at $25{ }^{\circ} \mathrm{C}$. The supernatant was discarded and the pellet resuspended in $20 \mu \mathrm{L} \mathrm{SCM}$ medium or PBS as indicated for attachment to lacy carbon grids with ultrathin Formvar $(200 \mathrm{~nm}$ mesh, Ladd Research Industries, Burlington, VT) for $30 \mathrm{~min}$ at RT. Cells were washed twice with SCM or PBS for 5 min 
at RT. Fixation was done with $2 \%$ glutaraldehyde in PBS for $5 \mathrm{~min}$ at RT followed by three washing steps with PBS, 5 min each. Permeabilization was done with $2.5 \%$ Triton in PBS for $5 \mathrm{~min}$ at RT followed by three washing steps with PBS, 5 min each. Blocking was performed with $5 \%$ goat serum in PBST for 30 min at RT (three washing steps with PBST, 5 min each). $\alpha$-NmPin antibody (1:20, rabbit) was incubated in $2 \%$ goat serum/PBST for $3 \mathrm{~h}$ at RT followed by three washing steps with PBST, 5 min each. Secondary $\alpha$-rabbit IgG antibody conjugated with $5 \mathrm{~nm}$ colloidal gold particles (1:20, goat, Sigma) in $2 \%$ goat serum/PBST was incubated for $1 \mathrm{~h}$ at RT (three washing steps with PBST, $5 \mathrm{~min}$ each). The antigen-antibody complex was fixed again with $2 \%$ glutaraldehyde in PBS for $5 \mathrm{~min}$ at RT followed by three washing steps in PBST, $5 \mathrm{~min}$ each. A final washing step was done for $15 \mathrm{~min}$ in $\mathrm{dd}_{2} \mathrm{O}$ and subsequent air drying overnight. Pictures were taken with a JEOL 1400 plus (AMT UltraVUE camera) at $80 \mathrm{kV}$. Data processing was done with ImageJ.

\section{Additional file}

Additional file 1: Figure S1. Sequence alignment of $\mathrm{NmPin}$ from $\mathrm{N}$. maritimus with various homologues from other phyla to investigate a potential conservation of the positively charged lysine patch of NmPin. Representatives were found by BLAST search. Each group was separately aligned to NmPin (green). Lysines of the patch (K5, K7, K31, K34, K37, K47, $\mathrm{K} 48, \mathrm{~K} 90)$ are labelled in dark blue and Arg or positively charged residues which are in close proximity to the conserved position are labelled in light blue. The positively charged patch on the surface of NmPin might be conserved also in other members of the TACK phylum. (PDF 464 kb)

\section{Acknowledgement}

We cordially thank Alma Rute for excellent technical assistance and the DFG (GRK 1431-1 and 1431-2) for financial support (PB). We thank the Microscope and Histology Facility of the University of Aberdeen for providing their equipment. We also thank Jacob Hargreaves for proofreading the manuscript.

\section{Authors' contributions}

The experiments were conceived by all authors. LH, FT and CL performed the practical work. All authors contributed to the writing of the manuscript. All authors read and approved the final manuscript.

\section{Competing interests}

The authors declare that they have no competing interests.

\section{Author details}

${ }^{1}$ Department of Structural and Medicinal Biochemistry, Centre for Medical Biotechnology, University of Duisburg-Essen, Universitätsstr. 1-4, 45141 Essen, Germany. ${ }^{2}$ Aberdeen Oomycetes Laboratory, Institute of Medical Sciences, University of Aberdeen, Foresterhill, AB25 2ZD Aberdeen, UK. ${ }^{3}$ Organic Geochemistry Group, MARUM Center for Marine Environmental Sciences, University of Bremen, Leobener Str. MARUM, 28359 Bremen, Germany.

Received: 3 March 2016 Accepted: 14 June 2016

Published online: 27 June 2016

\section{References}

1. Brandts JF, Halvorson HR, Brennan M. Consideration of the possibility that the slow step in protein denaturation reactions is due to cis-trans isomerism of proline residues. Biochemistry. 1975;14:4953-63.
2. Zimmerman SS, Scheraga HA. Stability of cis, trans, and nonplanar peptide groups. Macromolecules. 1976;9:408-16.

3. Stein RL. Mechanism of enzymatic and nonenzymatic prolyl cis-trans isomerization. Adv Protein Chem. 1993:44:1-24.

4. Schmid FX, Mayr LM, Mücke M, Schönbrunner ER. Prolyl isomerases: role in protein folding. Adv Protein Chem. 1993;44:25-66.

5. Fischer G, Bang H, Mech C. Nachweis einer Enzymkatalyse für die cis-transIsomerisierung der Peptidbindung in prolinhaltigen Peptiden. Biomed Biochim Acta. 1984;43:1101-11

6. Siekierka JJ, Hung SH, Poe M, Lin CS, Sigal NH. A cytosolic binding protein for the immunosuppressant FK506 has peptidyl-prolyl isomerase activity but is distinct from cyclophilin. Nature. 1989;341:755-7. doi:10.1038/341755a0.

7. Rahfeld JU, Schierhorn A, Mann K, Fischer G. A novel peptidyl-prolyl cis/ trans isomerase from Escherichia coli. FEBS Lett. 1994;343:65-9.

8. Sekerina E, Rahfeld JU, Müller J, Fanghänel J, Rascher C, Fischer G, et al. NMR solution structure of hPar14 reveals similarity to the peptidyl prolyl cis/ trans isomerase domain of the mitotic regulator hPin1 but indicates a different functionality of the protein. J Mol Biol. 2000;301:1003-17. doi:10. 1006/jmbi.2000.4013.

9. Rahfeld JU, Rücknagel KP, Schelbert B, Ludwig B, Hacker J, Mann K, et al. Confirmation of the existence of a third family among peptidyl-prolyl cis/ trans isomerases. Amino acid sequence and recombinant production of parvulin. FEBS Lett. 1994;352:180-4

10. Rulten S, Thorpe J, Kay J. Identification of eukaryotic parvulin homologues: a new subfamily of peptidylprolyl cis-trans isomerases. Biochem Biophys Res Commun. 1999;259:557-62. doi:10.1006/bbrc.1999.0828.

11. Lu KP, Hanes SD, Hunter T. A human peptidyl-prolyl isomerase essential for regulation of mitosis. Nature. 1996;380:544-7. doi:10.1038/380544a0.

12. Ranganathan R, Lu KP, Hunter T, Noel JP. Structural and functional analysis of the mitotic rotamase Pin1 suggests substrate recognition is phosphorylation dependent. Cell. 1997;89:875-86.

13. Zheng H, You H, Zhou XZ, Murray SA, Uchida T, Wulf G, et al. The prolyl isomerase Pin1 is a regulator of p53 in genotoxic response. Nature. 2002; 419:849-53. doi:10.1038/nature01116.

14. Pastorino L, Sun A, Lu P, Zhou XZ, Balastik M, Finn G, et al. The prolyl isomerase Pin1 regulates amyloid precursor protein processing and amyloid-beta production. Nature. 2006;440:528-34. doi:10.1038/nature04543.

15. Lee TH, Pastorino L, Lu KP. Peptidyl-prolyl cis-trans isomerase Pin1 in ageing, cancer and Alzheimer disease. Expert Rev Mol Med. 2011;13:e21. doi:10. 1017/S1462399411001906.

16. Bitto E, McKay DB. Crystallographic structure of SurA, a molecular chaperone that facilitates folding of outer membrane porins. Structure. 2002;10:1489-98.

17. Bitto E, McKay DB. The periplasmic molecular chaperone protein SurA binds a peptide motif that is characteristic of integral outer membrane proteins. J Biol Chem. 2003;278:49316-22. doi:10.1074/jbc.M308853200.

18. Hennecke G, Nolte J, Volkmer-Engert R, Schneider-Mergener J, Behrens S. The periplasmic chaperone SurA exploits two features characteristic of integral outer membrane proteins for selective substrate recognition. J Biol Chem. 2005;280:23540-8. doi:10.1074/jbc.M413742200.

19. Ricci DP, Schwalm J, Gonzales-Cope M, Silhavy TJ. The activity and specificity of the outer membrane protein chaperone SurA are modulated by a proline isomerase domain. MBio. 2013;4(4):e00540-13. doi:10.1128/mBio.00540-13.

20. Weininger U, Jakob RP, Kovermann M, Balbach J, Schmid FX. The prolyl isomerase domain of PpiD from Escherichia coli shows a parvulin fold but is devoid of catalytic activity. Protein Sci. 2010;19:6-18. doi:10.1002/pro.277.

21. Matern Y, Barion B, Behrens-Kneip S. PpiD is a player in the network of periplasmic chaperones in Escherichia coli. BMC Microbiol. 2010;10:251. doi: 10.1186/1471-2180-10-251.

22. Jacobs M, Andersen JB, Kontinen V, Sarvas M. Bacillus subtilis PrsA is required in vivo as an extracytoplasmic chaperone for secretion of active enzymes synthesized either with or without pro-sequences. Mol Microbiol. 1993:8:957-66.

23. Tossavainen H, Permi P, Purhonen SL, Sarvas M, Kilpeläinen I, Seppala R. NMR solution structure and characterization of substrate binding site of the PPlase domain of PrsA protein from Bacillus subtilis. FEBS Lett. 2006;580: 1822-6. doi:10.1016/j.febslet.2006.02.042.

24. Wahlström E, Vitikainen M, Kontinen VP, Sarvas M. The extracytoplasmic folding factor PrsA is required for protein secretion only in the presence of the cell wall in Bacillus subtilis. Microbiology. 2003;149:569-77.

25. Heikkinen $O$, Seppala R, Tossavainen $H$, Heikkinen S, Koskela H, Permi $P$, et al. Solution structure of the parvulin-type PPlase domain of Staphylococcus 
aureus PrsA-implications for the catalytic mechanism of parvulins. BMC Struct Biol. 2009:9:17. doi:10.1186/1472-6807-9-17.

26. Jaremko $\measuredangle$, Jaremko M, Elfaki I, Mueller JW, Ejchart A, Bayer $P$, et al. Structure and dynamics of the first archaeal parvulin reveal a new functionally important loop in parvulin-type prolyl isomerases. J Biol Chem. 2011;286: 6554-65. doi:10.1074/jbc.M110.160713.

27. Kühlewein A, Voll G, Hernandez Alvarez B, Kessler H, Fischer G, Rahfeld J, et al. Solution structure of Escherichia coli Par10: The prototypic member of the Parvulin family of peptidyl-prolyl cis/trans isomerases. Protein Sci. 2004; 13:2378-87. doi:10.1110/ps.04756704.

28. Behrens S, Maier R, de Cock H, Schmid FX, Gross CA. The SurA periplasmic PPlase lacking its parvulin domains functions in vivo and has chaperone activity. EMBO J. 2001;20:285-94. doi:10.1093/emboj/20.1.285.

29. Vitikainen M, Lappalainen I, Seppala R, Antelmann H, Boer H, Taira S, et al. Structure-function analysis of PrsA reveals roles for the parvulin-like and flanking $\mathrm{N}$ - and C-terminal domains in protein folding and secretion in Bacillus subtilis. J Biol Chem. 2004;279:19302-14. doi:10.1074/jbc.M400861200.

30. Hyyryläinen H, Marciniak BC, Dahncke K, Pietiäinen M, Courtin P, Vitikainen $\mathrm{M}$, et al. Penicillin-binding protein folding is dependent on the PrsA peptidyl-prolyl cis-trans isomerase in Bacillus subtilis. Mol Microbiol. 2010;77: 108-27. doi:10.1111/j.1365-2958.2010.07188.x.

31. Dartigalongue C, Raina S. A new heat-shock gene, ppiD, encodes a peptidyl-prolyl isomerase required for folding of outer membrane proteins in Escherichia coli. EMBO J. 1998;17:3968-80. doi:10.1093/emboj/17.14.3968.

32. Cahoon LA, Freitag NE, Prehna G. A structural comparison of Listeria monocytogenes protein chaperones PrsA1 and PrsA2 reveals molecular features required for virulence. Mol Microbiol. 2016. doi:10.1111/mmi.13367.

33. Walker CB, de la Torre JR, Klotz MG, Urakawa H, Pinel N, Arp DJ, et al. Nitrosopumilus maritimus genome reveals unique mechanisms for nitrification and autotrophy in globally distributed marine crenarchaea. Proc Natl Acad Sci U S A. 2010;107:8818-23. doi:10.1073/pnas.0913533107.

34. Lederer C, Heider D, van den Boom J, Hoffmann D, Mueller JW, Bayer P. Single-domain parvulins constitute a specific marker for recently proposed deep-branching archaeal subgroups. Evol Bioinform Online. 2011;7:135-48. doi:10.4137/EBO.S7683.

35. Könneke M, Schubert DM, Brown PC, Hügler M, Standfest S, Schwander T, et al. Ammonia-oxidizing archaea use the most energy-efficient aerobic pathway for CO2 fixation. Proc Natl Acad Sci U S A. 2014;111:8239-44. doi:10.1073/pnas. 1402028111

36. Stahl DA, de la Torre JR. Physiology and diversity of ammonia-oxidizing archaea. Annu Rev Microbiol. 2012;66:83-101. doi:10.1146/annurev-micro092611-150128.

37. Yaffe MB, Schutkowski M, Shen M, Zhou XZ, Stukenberg PT, Rahfeld JU, et al. Sequence-specific and phosphorylation-dependent proline isomerization: a potential mitotic regulatory mechanism. Science. 1997;278:1957-60.

38. Verdecia MA, Bowman ME, Lu KP, Hunter T, Noel JP. Structural basis for phosphoserine-proline recognition by group IV WW domains. Nat Struct Biol. 2000;7:639-43. doi:10.1038/77929.

39. Sun L, Wu X, Peng Y, Goh JY, Liou Y, Lin D, et al. Solution structural analysis of the single-domain parvulin TbPin1. PLoS One. 2012;7:e43017. doi:10.1371/ journal.pone.0043017.

40. Konagurthu AS, Whisstock JC, Stuckey PJ, Lesk AM. MUSTANG: a multiple structural alignment algorithm. Proteins. 2006;64:559-74. doi:10.1002/prot.20921.

41. Fanghänel J, Fischer G. Insights into the catalytic mechanism of peptidyl prolyl cis/trans isomerases. Front Biosci. 2004;9:3453-78.

42. Schouten S, Hopmans EC, Baas M, Boumann H, Standfest S, Könneke M, et al. Intact membrane lipids of "Candidatus Nitrosopumilus maritimus," a cultivated representative of the cosmopolitan mesophilic group I Crenarchaeota. Appl Environ Microbiol. 2008;74:2433-40. doi:10.1128/AEM.01709-07.

43. Pitcher A, Hopmans EC, Mosier AC, Park S, Rhee S, Francis CA, et al. Core and intact polar glycerol dibiphytanyl glycerol tetraether lipids of ammoniaoxidizing archaea enriched from marine and estuarine sediments. Appl Environ Microbiol. 2011;77:3468-77. doi:10.1128/AEM.02758-10.

44. Elling FJ, Könneke M, Lipp JS, Becker KW, Gagen EJ, Hinrichs K. Effects of growth phase on the membrane lipid composition of the thaumarchaeon Nitrosopumilus maritimus and their implications for archaeal lipid distributions in the marine environment. Geochim Cosmochim Acta. 2014 141:579-97. doi:10.1016/j.gca.2014.07.005.

45. de la Torre JR, Walker CB, Ingalls AE, Könneke M, Stahl DA. Cultivation of a thermophilic ammonia oxidizing archaeon synthesizing crenarchaeol. Environ Microbiol. 2008;10:810-8. doi:10.1111/j.1462-2920.2007.01506.x.
46. Könneke M, Bernhard AE, de la Torre JR, Walker CB, Waterbury JB, Stahl DA. Isolation of an autotrophic ammonia-oxidizing marine archaeon. Nature. 2005:437:543-6. doi:10.1038/nature03911.

47. Pelve EA, Lindås A, Martens-Habbena W, de la Torre JR, Stahl DA, Bernander R. Cdv-based cell division and cell cycle organization in the thaumarchaeon Nitrosopumilus maritimus. Mol Microbiol. 2011;82:555-66. doi:10.1111/j. 1365-2958.2011.07834.x

48. Albers S, Meyer BH. The archaeal cell envelope. Nat Rev Microbiol. 2011;9: 414-26. doi:10.1038/nrmicro2576.

49. Scholz C, Rahfeld J, Fischer G, Schmid FX. Catalysis of protein folding by parvulin. J Mol Biol. 1997;273:752-62. doi:10.1006/jmbi.1997.1301.

50. Rouvière PE, Gross CA. SurA, a periplasmic protein with peptidyl-prolyl isomerase activity, participates in the assembly of outer membrane porins. Genes Dev. 1996;10:3170-82.

51. Kennelly PJ. Protein Ser/Thr/Tyr phosphorylation in the Archaea. J Biol Chem. 2014;289:9480-7. doi:10.1074/jbc.R113.529412.

52. Lu PJ, Zhou XZ, Shen M, Lu KP. Function of WW domains as phosphoserineor phosphothreonine-binding modules. Science. 1999;283:1325-8.

53. Li Z, Li H, Devasahayam G, Gemmill T, Chaturvedi V, Hanes SD, et al. The structure of the Candida albicans Ess1 prolyl isomerase reveals a wellordered linker that restricts domain mobility. Biochemistry. 2005:44:6180-9. doi:10.1021/bi050115l.

54. Matena A, Sinnen C, van den Boom J, Wilms C, Dybowski JN, Maltaner R, et al. Transient domain interactions enhance the affinity of the mitotic regulator Pin1 toward phosphorylated peptide ligands. Structure. 2013;21:1769-77. doi:10.1016/j. str.2013.07.016

55. Yao JL, Kops O, Lu PJ, Lu KP. Functional conservation of phosphorylationspecific prolyl isomerases in plants. J Biol Chem. 2001;276:13517-23. doi:10. 1074/jbc.M007006200.

56. Uchida T, Fujimori F, Tradler T, Fischer G, Rahfeld JU. Identification and characterization of a $14 \mathrm{kDa}$ human protein as a novel parvulin-like peptidyl prolyl cis/trans isomerase. FEBS Lett. 1999:446:278-82.

57. Kelly S, Wickstead B, Gull K. Archaeal phylogenomics provides evidence in support of a methanogenic origin of the Archaea and a thaumarchaeal origin for the eukaryotes. Proc Biol Sci. 2011;278:1009-18. doi:10.1098/rspb. 2010.1427.

58. Guy L, Ettema TJG. The archaeal TACK' superphylum and the origin of eukaryotes. Trends Microbiol. 2011;19:580-7. doi:10.1016/j.tim.2011.09.002.

59. Williams TA, Foster PG, Cox CJ, Embley TM. An archaeal origin of eukaryotes supports only two primary domains of life. Nature. 2013;504:231-6. doi:10. 1038/nature12779.

60. Raymann K, Brochier-Armanet C, Gribaldo S. The two-domain tree of life is linked to a new root for the Archaea. Proc Natl Acad Sci U S A. 2015;112: 6670-5. doi:10.1073/pnas.1420858112.

61. Zhang J, Nakatsu Y, Shinjo T, Guo Y, Sakoda H, Yamamotoya T, et al. Par14 protein associates with insulin receptor substrate 1 (IRS-1), thereby enhancing insulin-induced IRS-1 phosphorylation and metabolic actions. J Biol Chem. 2013; 288(28):20692-701. doi:10.1074/jbc.M113.485730. Epub 2013 May 29.

62. Fujiyama-Nakamura S, Yoshikawa H, Homma K, Hayano T, Tsujimura-Takahashi T, Izumikawa K, et al. Parvulin (Par14), a peptidyl-prolyl cis-trans isomerase, is a novel rRNA processing factor that evolved in the metazoan lineage. Mol Cell Proteomics. 2009;8(7):1552-65. doi:10.1074/mcp.M900147-MCP200.

63. Mulgrew-Nesbitt A, Diraviyam K, Wang J, Singh S, Murray P, Li Z, et al. The role of electrostatics in protein-membrane interactions. Biochim Biophys Acta. 2006;1761:812-26. doi:10.1016/j.bbalip.2006.07.002.

64. Honig B, Nicholls A. Classical electrostatics in biology and chemistry. Science. 1995;268:1144-9.

65. Boddey JA, O'Neill MT, Lopaticki S, Carvalho TG, Hodder AN, Nebl T, et al. Export of malaria proteins requires co-translational processing of the PEXEL motif independent of phosphatidylinositol-3-phosphate binding. Nat Commun. 2016;7:10470.

66. Messner P, Pum D, Sára M, Stetter KO, Sleytr UB. Ultrastructure of the cell envelope of the archaebacteria Thermoproteus tenax and Thermoproteus neutrophilus. J Bacteriol. 1986;166:1046-54.

67. Baumeister W, Lembcke G. Structural features of archaebacterial cell envelopes. J Bioenerg Biomembr. 1992;24:567-75.

68. Albers S, Szabo Z, Driessen AJM. Protein secretion in the Archaea: multiple paths towards a unique cell surface. Nat Rev Microbiol. 2006;4:537-47. doi: 10.1038/nrmicro1440.

69. Ellen AF, Zolghadr B, Driessen AMJ, Albers S. Shaping the archaeal cell envelope. Archaea. 2010;2010:608243. doi:10.1155/2010/608243. 
70. Peters J, Nitsch M, Kühlmorgen B, Golbik R, Lupas A, Kellermann J, et al. Tetrabrachion: a filamentous archaebacterial surface protein assembly of unusual structure and extreme stability. J Mol Biol. 1995;245:385-401.

71. Peters J, Baumeister W, Lupas A. Hyperthermostable surface layer protein tetrabrachion from the archaebacterium Staphylothermus marinus: evidence for the presence of a right-handed coiled coil derived from the primary structure. J Mol Biol. 1996;257:1031-41. doi:10.1006/jmbi.1996.0221.

72. Kessler D, Papatheodorou P, Stratmann T, Dian EA, Hartmann-Fatu C, Rassow J, et al. The DNA binding parvulin Par17 is targeted to the mitochondrial matrix by a recently evolved prepeptide uniquely present in Hominidae. BMC Biol. 2007:5:37. doi:10.1186/1741-7007-5-37.

73. Grum D, Franke S, Kraff O, Heider D, Schramm A, Hoffmann D, et al. Design of a modular protein-based MRI contrast agent for targeted application. PLoS One. 2013;8:e65346. doi:10.1371/journal.pone.0065346.

74. Martens-Habbena W, Berube PM, Urakawa H, de la Torre JR, Stahl DA. Ammonia oxidation kinetics determine niche separation of nitrifying Archaea and Bacteria. Nature. 2009:461:976-9. doi:10.1038/nature08465.

75. Kofron JL, Kuzmic P, Kishore V, Colón-Bonilla E, Rich DH. Determination of kinetic constants for peptidyl prolyl cis-trans isomerases by an improved spectrophotometric assay. Biochemistry. 1991;30:6127-34.

76. Vranken WF, Boucher W, Stevens TJ, Fogh RH, Pajon A, Llinas M, et al. The CCPN data model for NMR spectroscopy: development of a software pipeline. Proteins. 2005;59:687-96. doi:10.1002/prot.20449.

77. López-Méndez B, Güntert P. Automated protein structure determination from NMR spectra. J Am Chem Soc. 2006;128:13112-22. doi:10.1021/ja061136l.

78. Krieger E, Koraimann G, Vriend G. Increasing the precision of comparative models with YASARA NOVA-a self-parameterizing force field. Proteins. 2002; 47:393-402.

79. Yan J, Wen W, Xu W, Long J, Adams ME, Froehner SC, et al. Structure of the split PH domain and distinct lipid-binding properties of the PH-PDZ supramodule of alpha-syntrophin. EMBO J. 2005;24:3985-95. doi:10.1038/sj. emboj.7600858.

80. Krojer T, Sawa J, Schäfer E, Saibil HR, Ehrmann M, Clausen T. Structural basis for the regulated protease and chaperone function of DegP. Nature. 2008; 453:885-90. doi:10.1038/nature07004.

81. Trent JD, Kagawa HK, Yaoi T, Olle E, Zaluzec NJ. Chaperonin filaments: the archaeal cytoskeleton? Proc Natl Acad Sci U S A. 1997;94:5383-8.

82. Krieger E, Nielsen JE, Spronk CA, Vriend G. Fast empirical pKa prediction by Ewald summation. J Mol Graph Model. 2006;25:481-6. doi:10.1016/j.jmgm. 2006.02.009

83. Bayer E, Goettsch S, Mueller JW, Griewel B, Guiberman E, Mayr LM, et al. Structural analysis of the mitotic regulator hPin 1 in solution: insights into domain architecture and substrate binding. J Biol Chem. 2003;278:26183-93. doi:10.1074/jbc.M300721200.

84. Mueller JW, Link NM, Matena A, Hoppstock L, Rüppel A, Bayer P, et al. Crystallographic proof for an extended hydrogen-bonding network in small prolyl isomerases. J Am Chem Soc. 2011;133:20096-9. doi:10.1021/ja2086195.

85. Landrieu I, Wieruszeski J, Wintjens R, Inzé D, Lippens G. Solution structure of the single-domain prolyl cis/trans isomerase PIN1At from Arabidopsis thaliana. J Mol Biol. 2002:320:321-32. doi:10.1016/S0022-2836(02)00429-1.

86. Bailey ML, Shilton BH, Brandl CJ, Litchfield DW. The dual histidine motif in the active site of Pin1 has a structural rather than catalytic role. Biochemistry. 2008:47:11481-9. doi:10.1021/bi800964q.

\section{Submit your next manuscript to BioMed Central and we will help you at every step:}

- We accept pre-submission inquiries

- Our selector tool helps you to find the most relevant journal

- We provide round the clock customer support

- Convenient online submission

- Thorough peer review

- Inclusion in PubMed and all major indexing services

- Maximum visibility for your research

Submit your manuscript at www.biomedcentral.com/submit 